Journal of the Egyptian Society of Parasitology, Vol.43, No.3, December 2013

J. Egypt. Soc. Parasitol., 43(3), 2013: 797 - 804

\title{
CONSUMPTION HAZARDS OF CATTLE LIVER INFECTED WITH FASCIOLA SPP.: II. EXPERIMENTAL STUDY ON RATS
}

\section{By}

FAROUK M. EL-TELLAWY ${ }^{1}$, REFAAT M. KHALIFA ${ }^{2^{*}}$, MONA K. ABD EL-KADER ${ }^{3}$, AMANY O. MOHAMED ${ }^{4}$ and NOHA S. AHMED ${ }^{5}$

Nutrition Technology, Institute of Environmental Studies and Researches ${ }^{1}$, Departments of Parasitology ${ }^{2}$ and Biochemistry ${ }^{4}$, Faculty of Medicine, Assiut University, Department of Nutrition ${ }^{3}$, Faculty of Home Economics, Helwan University, Department of Home Economics ${ }^{5}$,Faculty of Specific

Education, Al- Fayoum University, Egypt

*Correspondence: Dr. Khalifa; rkhalifa_eg@yahoo.com

\begin{abstract}
This study evaluated and revealed the consumption hazards of cattle liver infected with Fasciola spp. and revealed its effects on the serum estimation of liver enzyme (ALT) on experimental rats. A total of 42 Wister albino rats were classified into 7 groups. Four groups were fed on raw and cooked cattle liver with various intensity of Fasciola spp. infection. Two groups were fed on raw and cooked normal cattle liver (positive control), and one group served as negative control. Histopathology of the rats' liver revealed hydropic degeneration, congestion with dilatation of the central vein and sinusoids and focal areas of necrosis. The intestine samples showed degenerative changes and necrobiosis of the villar epithelium with inflammatory cell infiltration. Moreover, a slight increase was noticed in the liver enzyme ALT which is known to be an important marker of liver destruction.
\end{abstract}

Key words: Fasciola spp., rats, Histopathology, liver, intestine, ALT.

\section{Introduction}

Cooked liver dishes are delicious to worldwide population, not only for its nice taste, but also for its high nutritive value. Moreover, in some Arabic countries it is consumed raw, just after slaughtering of sheep and goats on basis of a traditional belief that it gives more nutritional value; particularly in underweight and anemic individuals. No doubt liver is an excellent nutritive organ, as an essential source of vitamin A, iron, zinc, copper and manganese, and a very good source of protein, vit- amin $\mathrm{D}$, vitamin $\mathrm{C}$, riboflavin, thiamine, niacin, vitamin B6, folate, vitamin B12, pantothenic acid, phosphorus and selenium (Webb, 2008). Cattle are exposed to the liver flukes (Fasciola spp.), which inhabit the bile ducts and feed on blood and hepatocytes (Urquhart et al, 1996; Hussein and Khalifa, 2008). Their excretions and toxic metabolic byproducts lead to pathological changes in the liver and bile ducts (Radostits et al, 2000; Mbuh and Mbwaye, 2005).

Studies on fascioliasis were directed towards saving the livestock from the 
serious effects of this parasite (Raadsma et al, 2007, Alcala-Canto et al, 2007; Abd Ellah et al, 2007; Saleh, 2008). However, little is known about

The present work aimed to reveal the effect of human consumption hazards of infected cattle liver with Fasciola spp. experimentally in albino rats by studying the histopathological pictures of the liver and intestine and liver enzyme (ALT).

\section{Material and Methods}

Preparation of liver diets and experimental feeding pattern: Healthy cattle livers were collected from slaughter houses in Assiut City, after strict inspection examination. They were divided into two parts, one was kept raw and the other was cooked by braising. Each part was cut into small pieces and weighed to be $5 \mathrm{gm}$ liver/rat, then kept in the freezer. Cattle livers infected with Fasciola spp. were classified according to worm burden into moderately infected group (5-20 worms $/ \mathrm{kg}$ ) and heavily infected group (more than 20 worms $/ \mathrm{kg}$ ). These samples were prepared as the previous healthy samples.

A total of 42 Wister albino rats aged 4 weeks were classified into 7 groups, six rats in each group. All groups were fed on granulated standard feed, and raw or cooked cattle liver every other day as follows: G1: Negative control, the effect of such infection on the nutritional value of these livers and the hazards of their human consumption.

fed on granulated standard feed only, G2: Positive control, fed on raw uninfected cattle liver, G3: Positive control, fed on cooked un-infected cattle liver, G4: Fed on raw moderately infected cattle liver, G5: Fed on cooked moderately infected cattle liver, G6: Fed on raw heavily infected cattle liver and G7: Fed on cooked heavily infected cattle liver.

Histopathology of rat's liver and intestine: All rats were sacrificed after three months and their livers and parts of the small intestine were collected and fixed in $10 \%$ formalin. The samples were labeled and sent to the Pathology Department, Faculty of Veterinary Medicine, Assiut University to be processed for histopathological examination

Rats' sera for estimation of ALT enzyme: Sera from control and infected groups were collected to be used in colorimetric determination of the liver enzyme; Alanine aminotransferase (ALT) activity (Breuer, 1996) from Spectrum cat. REF:262 005 (5/20ml)

\section{Results}

The results are shown in figures $1-6$ (liver) and 7 - 12 (intestine) and table1.

Table 1: Determination of (ALT) activity:

\begin{tabular}{|l|c|c|}
\hline \multicolumn{1}{|c|}{ Tested Groups } & \multicolumn{2}{c|}{ Liver enzyme ALT U/L } \\
\hline Control negative $(\mathrm{G} 1)$ & raw liver & cooked liver \\
\hline Fed & $7.80 \pm 1.95$ & $8.91 \pm 1.84$ \\
\hline Control positive $(\mathrm{G} 2+\mathrm{G} 3)$ & $10.67 \pm 3.63$ & $10.97 \pm 1.91$ \\
\hline Fed on moderately infected liver $(\mathrm{G} 4+\mathrm{G} 5)$ & $12.73 \pm 4.60^{*}$ & $12.70 \pm 2.69^{*}$ \\
\hline \multicolumn{2}{|c|}{ Fed on heavily infected liver(G6 $+\mathrm{G} 7)$} & \\
\hline \multicolumn{2}{|c|}{$\mathrm{p}<0.05$}
\end{tabular}


There was slight increase in ALT in sera of control positive groups as compared to control negative. Rats of G4 \& G5showed insignificant increase in ALT serum levels, while rats of G6 \& G7 showed marked significant increase in both raw and cooked cattle livers.

\section{Discussion}

Fasciolosis is one of the major public health problems worldwide. In Egypt, the zoonotic fascioliasis (Haseeb et al, 2003) ectoptic forms (Rashed et al, 2010), fascioliasis was also reported in edible (El-Shazly et al, 2005) and nonedible animals (Haridy et al, 2007) and even in rodents (Haridy et al, 2003). Also, its' snails intermediate host are distributed in many governorates (AboMadyan et al, 2005)

This work was done for the first time in Egypt as a trial to study the effect of human consumption of cattle liver infected with Fasciola spp. Liver samples were served in two ways; raw and cooked by braising method as this is the commonly used in liver cooking. However, the habit of consumption of raw liver may be met with in certain countries and this may lead to pharyngeal fascioliasis as a result of attachment of immature worms to the pharyngeal wall, which cause oedema and inflammation of the pharynx that may lead to suffocation (Fica et al, 2012).

Rat liver samples revealed correlated pathologic effects with the intensity of infection of bovine livers. So, rat groups fed with moderately infected livers showed congestion with dilatation of the central vein and sinusoides, which may indicate increase in the blood supply to the liver leading to dilatation of vasculature caused by the effects of Fasciola and its metabolites. This agreed with Yoshida et al. (1996) in natural and experimental fascioliasis. Rats fed on heavily infected livers showed the start of necrosis and hydropic degeneration of some hepatocytes, caused by the waste product effects of Fasciola worms or their excretory products on the infected cattle liver. This coincides with Ganga et al. (2006) as the metabolites discharged by the parasite in situ may be a cause of pathological lesions in the liver and anemia. The role of amino acid (proline) secreted by Fasciola proved to be toxic to the host and cause anemia by destroying red blood cells (Ganga et al, 2006; Adarosy et al, 2013).

Rat intestinal section showed changes in the villar epithelium. Both the control positive groups showed infiltration of intestinal villi with inflammatory cells, which may be a reaction to the liver protein diet comparing to the negative control group.

Rats fed on moderately infected raw and cooked liver showed the intestine with degenerative changes in the villar epithelium, this may be due to the absorption of the secretory products of Fasciola worms present in cattle livers. More pathological reactions were observed in rats fed on heavily infected raw and cooked liver, which coincide with the intensity of infection and subsequently with large amount of secretory products and waste byproducts of Fasciola worms. Molina (2005) wondered whether both excretory products and metabolic byproducts of Fasciola 
in liver have any effect on the human consumption. Sothoeun et al. (2006) reported that the pathological reactions caused by Fasciola spp. in the liver were permanent and untreated. Therefore, people living in developing countries with high prevalence rate of cattle fascioliasis are subjected to prolonged consumption of infected livers (particularly in cheap unsanitary restaurants which illegally buy moderately and even highly infected livers from house slaughtered animals and utilize them in preparation of liver meals) which is potentially pathogenic on the long run. Meanwhile, these livers lack the nutritional value needed to feed individuals suffering from anemia and nutritional deficiency diseases.

In the present study, ALT was selected as a marker of liver destruction, and was considered to be specific for hepatic damage in small animals, as cat, dogs and rats (Tennant, 1997). Atakisi et al. (2006) and Siemieniuk et al. (2008) reported that ALT is a sensitive indicator of liver cell injury used to identify liver diseases.

Rats sera showed a slight increase in ALT of control positive groups, which may be due to the protein content in liver diets. However, marked increase was observed in all the tested groups, and significant in groups fed on both heavily infected raw and cooked bovine livers. This increase can be explained by the metabolic disturbance in rats as a response to the secretory products released by Fasciola worms in the consumed bovine liver. Serradell et al, (2007) stated that the diminution in eosinophil survival in early infection could be a parasite strategy in order to prevent a host immune response.

Molina (2005) wondered that the role of the toxic substances emanating from liver fluke were speculated upon by many authors, but not yet determined whether both excretory products and metabolic byproduct of Fasciola in the liver have any effect on the human consumption.

\section{Conclusion}

Generally speaking, zoonotic fascioliasis is a worldwide problem particularly in edible animals rearing countries. The consumption of fascioliasis infected liver is risky hazardous to man.

\section{Acknowledgement}

The authors are grateful to Prof. Salah Afify and Prof. Sarry Khaleel, Department of Pathology, Faculty of Veterinary Medicine, Assiut University, for their kind assistance in the histopathological study.

\section{References}

Abd Ellah, M, Okada, K, Yasuda, J, 2007: Oxidative stress and bovine liver disease: Role of glutathione peroxidase and glucose 6- phosphate dehydrogenase. Jpn. J. Vet. Res. 54, 4:163-73.

Abo-Madyan, AA, Morsy, TA, Motawea, SM, El Garhy, MF, Massoud, A MA, 2005: Spot light survey on freshwater snails of medical importance in Al Fayoum Governorate, Egypt. J. Egypt. Soc. Parasitol. 35, 1:49-58.

Adarosy, HA, Gad, YZ, El-Baz, SA, El-Shazly, AM, 2013: Changing pattern of fascioliasis prevalence early in the 3rd millennium in Dakahlia Gover- 
norate, Egypt: an update. J. Egypt. Soc. Parasitol. 43, 1:275-86.

Alcala-Canto, Y, Ibarra-Yalarde, F, Sumano-Lopez, H, et al, 2007: Effect of cysteine protease inhibitor on Fasciola hepatica (liver fluke) fecundity, egg viability, parasite burden and size in experimentally infected sheep. Parasitol. Res. 100: 461-5.

Atakisi, E, Karapehlivan, M, Atakisi, O, et al, 2006: Adenosene deaminase and biochemical in liver function tests, the dermatophytic cattle. Bull. Vet. Inst. Pulawy 50:481-3.

Breuer, J, 1996: Reports on the symposium drug effects in clinical chemistry methods. Eur. J. Chem. Clin. Biochem. 34: 385-6.

El-Shazly, AM, Abdel-Magied, AA, EI-Nahas, HA, El-Metwaly, MS, Morsy, TA, et al, 2005: On the main reservoir host of Fasciola in Dakahlia Governorate, Egypt. J. Egypt. Soc. Parasitol. 35, 1:243-52.

Fica, A, Dabanch, J, Farias, C, Castro, M, Jercic, MI, et al, 2012: Acute fascioliasis-clinical and epidemiological features of four patients in Chile. Clin. Microbiol. Infect. 18, 1:91-6.

Ganga, G, Varshney, J, Sharma, R, 2006: Effect of Fasciola gigantica excretory secretory antigen on rat hematological indices. J. Vet. Sci. 7, 2:1235.

Haridy, FM, Morsy, TA, Ibrahim, B B, Abdel Gawad, AG, Mazyad, SA, 2003: Rattus rattus: a new host for fascioliasis. J. Egypt. Soc. Parasitol. 33, 2: 647-8.

Haridy, FM, Morsy, GH, Abdou, N E, Morsy, TA, 2007: Zoonotic fascio- liasis in donkeys: ELISA (Fges) and postmortum examination in the Zoo, Giza, Egypt. J. Egypt. Soc. Parasitol. 37, 3:1101-10.

Haseeb, AN, EI Shazly, AM, Arafa, MAS, Morsy, ATA, 2003: Clinical, laboratory and ultrasonography features of proven human fascioliasis. J. Egypt. Soc. Parasitol. 33, 2: 397-412.

Hussein, A, Khalifa, R, 2008: Experimental infections with Fasciola in snails, mice and rabbits. Parasitol. Res. 102:1165-70.

Mbuh, J, Mbwaye, J, 2005: Serological changes in goats experimentally infected with Fasciola gigantica in Buea sub-division of .W.P. Cameroon. Vet. Parasitol. 131, 3/4:255-9.

Molina, E, 2005: Serum interferongamma and Interlukin -6 and -8 during infection with Fasciola gigantica in cattle and buffaloes. J. Vet. Sci., 6:1359.

Raadsma, H, Kingsford, N, Suharyata, H, et al, 2007: Host responses during experimental infection with Fasciola gigantica and Fasciola hepatica in merino sheep: I. Comparative immunological and plasma biochemical changes during early infection. Vet. Parasitol. 143, 28:275-86.

Radostits, O, Gay, C, Blood, D, Hinchcliff, K, 2000: Veterinary Medicine. The $9^{\text {th }}$ edition; Baillier-Tindall, London, The United Kingdom.

Rashed, AA, Khalil, HHM, Morsy, A TA, 2010: Zoonotic ectopic fascioliasis: review and discussion. J. Egypt. Soc. Parasitol. 40, 3:591-60

Saleh, M, 2008: Circulating oxidative stress status in desert sheep naturally 
infected with Fasciola hepatica. Vet. Parasitol. 154:262-9.

Serradell, MC, Guasconi, L, Cervi, L, Chiapello, LS, Masih, DT, 2007: Excretory-secretory products from $\mathrm{Fa}$ sciola hepatica induce eosinophil apoptosis by a caspase-dependent mechanism. Vet. Immunol. Immunopathol. 117, 3/4:197-202

Siemieniuk, E, Kolodziejczyk, L, Skrzydlewska, E, 2008: Oxidative modifications of rat liver cell components during Fasciola hepatica infection. Toxicol. Mech. Meth.18, 6:519-24

Sothoeun, S, Davun, H, Copeman, B, 2006: Abattoir study on Fasciola gi- gantica in Cambodian cattle. Trop. Anim. Hlth. Prod. 38:113-5.

Tennant, C, 1997: Hepatic function. In: Clinical Biochemistry of Domestic Animals. The $5^{\text {th }}$ edition; Academic Press; San Diego.

Urquhart, G, Armour, J, Duncan, J, et al, 1996: Veterinary Parasitology, $2^{\text {nd }}$ Edition, UK, Blackwell Science.

Webb, G, 2008: A Health Promotion Approach. In: Nutrition. $3^{\text {rd }}$ ed., Hodder Arnold Publishing, London, UK.

Yoshida, T, Nagahama, K, Miyandaki, KE, 1996: Pathology of eosinophilic phlebitis in the liver of Japanese black cattle. J. Jap. Vet. Med. Assoc. 49:751-4.

\section{Explanation of figures}

Fig.1: Section of rat liver of G1 \& 2, showing nearly normal appearance.

Fig.2: Section of rat liver of G3, showing slight hydropic degenerative changes in hepatocytes.

Fig.3: Section of rat liver of G4, showing dilatation of central vein and sinusoids (green arrow) with marked hydropic degeneration of hepatocytes (black arrows).

Fig.4: Section of rat liver of G5, showing liver congestion manifested by RBCs in dilated sinusoids (arrows).

Fig.5: Section of rat liver of G6, showing focal areas of necrosis in hepatocytes (Fig 6a), hydropic degeneration of hepatocytes (black arrows) and liver congestion in dilated sinusoids (green arrow) (Fig. 6b).

Fig.6: Section of rat liver of G7, showing focal areas of necrosis with kupffer cell reaction (Fig 6a), congestion (green arrow) and dilatation of sinusoids (black arrow) (Fig. 6b).

Fig.7\&8: Sections of rat intestine of G2 \& G3, in both groups the intestinal villi infiltrated with mononuclear cells (star) and eosinophils (arrows).

Fig.9\&10: Sections of rat intestine of G4 \& G5, in both groups intestine showed degenerative changes in villar epithelium with increase in number of goblet cells.

Fig.11: Section of rat intestine of G6, showing thickened intestinal villi, infiltrated with mononuclear and eosinophil cells (star) and necrobiosis in villar epithelium (arrows).

Fig.12: Section of rat intestine of G7, showing marked thickening of the intestinal villi with heavy mononuclear and eosinophilic cell infiltration (Fig. 12a), in addition to necrobiosis of the villar epithelium (Fig.12b). 

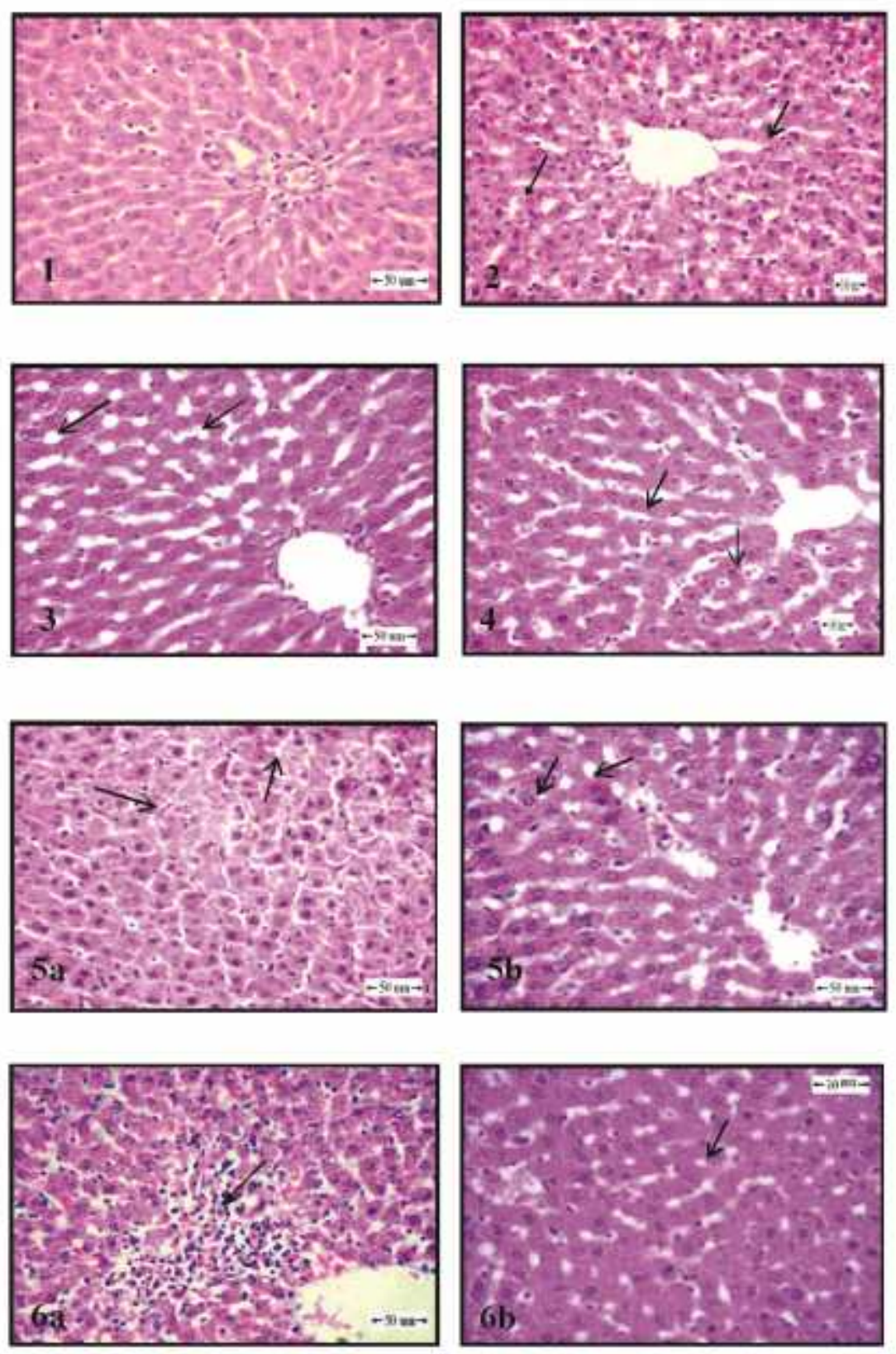

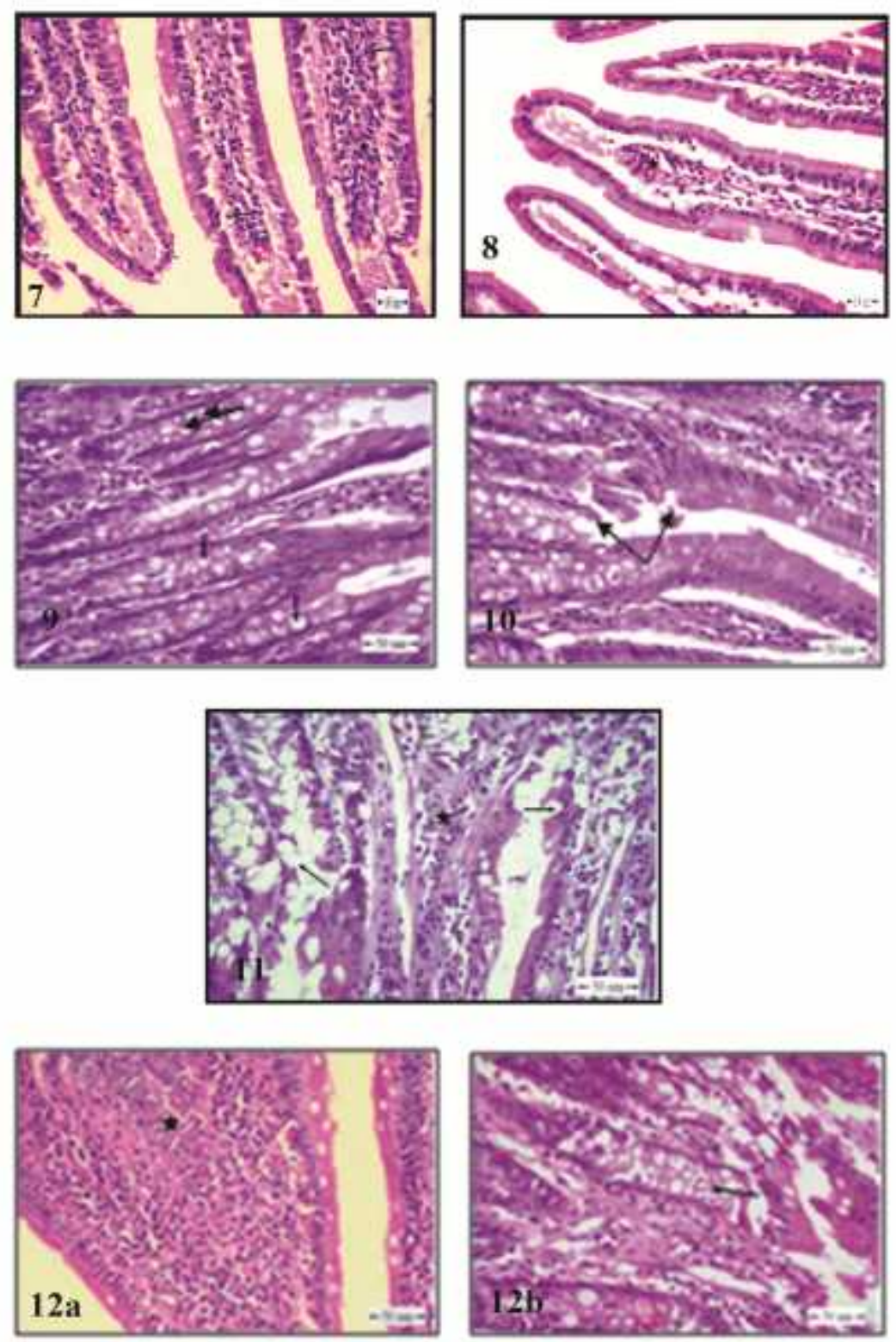